\title{
Production of Long-chain Alcohols by Yeasts
}

\author{
By MICHAEL J. WHITE, ${ }^{1}$ ROGER C. HAMMOND ${ }^{2}$ AND \\ ANTHONY H. ROSE ${ }^{1 *}$ \\ ${ }^{1}$ Zymology Laboratory, School of Biological Sciences, Bath University, Bath, \\ Avon BA2 7AY, UK \\ ${ }^{2}$ Unilever Research Laboratory, Colworth Laboratory, Colworth House, Sharnbrook, \\ Bedford MK44 ILQ, UK
}

(Received 16 February 1987; revised 12 March 1987)

Fourteen yeast strains from six genera were analysed for the presence of long-chain alcohols. Six strains from three genera contained long-chain alcohols, highest levels being found in Candida albicans. The alcohols were identified and determined by TLC, GLC and GLC-MS. The major long-chain alcohols synthesized by these organisms were saturated, primary alcohols with $\mathrm{C}_{14}$, $\mathrm{C}_{16}$ or $\mathrm{C}_{18}$ chain length. Unsaturated long-chain alcohols were not detected. In all strains that produced long-chain alcohols, the relative proportions were $C_{16}>C_{18}>C_{14}$. Long-chain alcohol contents were higher in organisms from anaerobically, as compared with aerobically, grown cultures reaching about $650 \mu \mathrm{g}$ (g dry wt organisms) $)^{-1}$ in stationary-phase cultures of $C$. albicans. In cultures of $C$. albicans, synthesis of long-chain alcohols occurred only after the end of exponential growth. The alcohols were predominantly present as free alcohols. The fatty-acyl chain-length profile of the triacylglycerol and to a lesser extent the sterol/wax ester fractions from $C$. albicans reflected that of the long-chain alcohols produced by this yeast.

\section{INTRODUCTION}

Long-chain alcohols occur as components of animal, higher plant and microbial lipids as free alcohols, precursors of glycerol ether lipids and in combination with carboxylic acids as wax esters (Mahadevan, 1978; Harwood \& Russell, 1984). Among micro-organisms that synthesize long-chain alcohols, bacteria have been studied most intensively (Stewart \& Kallio, 1959; Raymond \& Davis, 1960; Baptist et al., 1963; Day et al., 1970; Allen et al., 1971; Naccarato et al., 1972; Lloyd \& Russell, 1983). Some long-chain alcohol-containing bacteria, such as mycobacteria (Ratledge, 1976), have been studied because of their medical importance. Other bacteria have been investigated for their industrial importance in, for example, degradation of oil spillage (Higgins \& Gilbert, 1978). In oil-degrading micro-organisms, long-chain alcohols are produced as intermediates in terminal oxidation of alkanes, and may also be found esterified with long-chain carboxylic acids which are produced by further oxidation of the alcohols (Ratledge, 1978; Britton, 1984). When grown on carbon sources other than alkanes, some bacteria synthesize long-chain primary alcohols by reduction of CoA esters of long-chain carboxylic acids which arise either from activity of the fatty acid synthase (Day et al., 1970; Naccarato et al., 1972; Lloyd \& Russell, 1983) or are supplied exogenously (Naccarato et al., 1974; Lloyd \& Russell, 1983).

Some yeasts are able to grow on alkanes (Britton, 1984) and certain of these organisms may accumulate wax esters containing long-chain alcohols. These yeasts include Candida guilliermondii (Muratov et al., 1979) and Rhodotorula glutinis (Zalashko et al., 1979; Zalashko \& Salokhina, 1982). Reports of long-chain alcohol production by yeasts grown on non-alkane

Abbreviations: PCMB, p-chloromercuribenzoate; TMS ethers, trimethylsilyl ethers. 
substrates are rare. Davidova et al. (1978) reported that wax esters were detectable in glucosegrown Candida tropicalis harvested from exponential-phase cultures, although their synthesis was more prolific when this yeast was grown on alkanes. The present paper reports synthesis of long-chain alcohols by several yeasts in media containing glucose as the carbon source.

\section{METHODS}

Organisms. The yeasts used were Candida albicans NCYC 1467, C. bombicola NCYC 1449, C. maltosa Colworth Microbial Culture Collection (CMCC) 3152, C. ingens NCYC 822, C. utilis NCYC 168, C. utilis NCYC 707, Debaryomyces hansenii NCYC 9, Pichia fermentans NCYC 850, Rhodotorula glutinis NCYC 59, Rh. glutinis CMCC 2272, Rh. rubra NCYC 195, Rhodotorula sp. ATCC 20254, Saccharomyces cerevisiae Y 185 (a gift from J. R. Woodward, Department of Biotechnology, University of Leeds, UK) and Saccharomycopsis (Yarrowia) lipolytica ATCC 20225. They were maintained at $4^{\circ} \mathrm{C}$ on slopes of malt extract-yeast extract-glucose-mycological peptone (MYGP) agar (Wickerham, 1951).

Experimental cultures. Organisms were grown aerobically in a medium containing $\left(1^{-1}\right)$ : glucose, $20 \mathrm{~g}$; $\left(\mathrm{NH}_{4}\right)_{2} \mathrm{SO}_{4}, 3.0 \mathrm{~g} ; \mathrm{KH}_{2} \mathrm{PO}_{4}, 4.5 \mathrm{~g}$; yeast extract (Lab M), $1.0 \mathrm{~g} ; \mathrm{MgSO}_{4} .7 \mathrm{H}_{2} \mathrm{O}, 25 \mathrm{mg}$; and $\mathrm{CaCl}_{2} .2 \mathrm{H}_{2} \mathrm{O}, 25 \mathrm{mg}$ (adjusted to $\mathrm{pH} 4.5$ with $\mathrm{HCl}$ ). Growth under self-induced anaerobic conditions used the same medium except that the concentration of glucose was $200 \mathrm{~g} \mathrm{l}^{-1}$ and that of yeast extract $4 \mathrm{~g}^{-1}$. One-litre portions of medium were dispensed into 21 round flat-bottomed flasks and sterilized by autoclaving at $6.89 \times 10^{4} \mathrm{~Pa}$ for $1 \mathrm{~min}$. Flasks used for aerobic growth were plugged with cotton wool, and those used for self-induced anaerobic growth were fitted with fermentation locks (Beavan et al., 1982). Starter cultures $(100 \mathrm{ml}$ medium in a $250 \mathrm{ml}$ flask) were inoculated with a pinhead of organisms from a slant culture, and incubated for $48 \mathrm{~h}$ at $30^{\circ} \mathrm{C}$ on an orbital shaker (200 r.p.m.). Experimental cultures used in the survey of long-chain alcohol production were inoculated with $1 \mathrm{ml}$ of starter culture; those used for further studies were inoculated with a portion of starter culture containing $10 \mathrm{mg}$ dry wt organisms. Cultures were incubated aerobically as described by Patching \& Rose (1969) and under self-induced anaerobic conditions as described by Beavan et al. (1982). The latter cultures are described as anaerobic in this paper. Growth was followed by measuring optical density at $600 \mathrm{~nm}$; measurements were related to the dry wt of each yeast strain using an appropriate standard curve. At the times indicated, organisms were harvested by centrifugation at $6000 \mathrm{~g}$ at $4^{\circ} \mathrm{C}$ and washed twice with water.

Lipid extraction. Before harvesting, $2 \mathrm{ml}$ solution containing $10 \mathrm{mg}$ each of cycloheximide and chloramphenicol, and where indicated $10 \mathrm{ml} 50 \mathrm{mM}-\mathrm{PCMB}$ in methanol, were injected into the culture which was incubated for a further $15 \mathrm{~min}$. Lipids were extracted from washed organisms by a modification of the Folch et al. (1957) procedure. Washed organisms were resuspended in $20 \mathrm{ml}$ methanol and shaken in a Braun homogenizer for four periods of $30 \mathrm{~s}$ at speed 2 (4000 r.p.m.) with glass beads ( $40 \mathrm{~g}$; Sigma type V; $0.45-0.50 \mathrm{~mm}$ diam.). The sample bottle was cooled with expanding $\mathrm{CO}_{2}$ during homogenization. Chloroform was added to the suspension to give $2: 1(\mathrm{v} / \mathrm{v})$ chloroform/methanol, and the mixture stirred magnetically for $2 \mathrm{~h}$ at room temperature $\left(18-22^{\circ} \mathrm{C}\right)$. The suspension was then filtered through Whatman no. 44 filter paper and the extraction procedure repeated on the residue. Extracts were pooled, washed with $0.25 \mathrm{vol} .0 .88 \%(\mathrm{w} / \mathrm{v}) \mathrm{KCl}$ and the mixture left to separate overnight at $-20^{\circ} \mathrm{C}$. The lower organic phase was removed, taken to dryness using a rotary evaporator, and the residue immediately dissolved in $1 \mathrm{ml}$ light petroleum (b.p. $60-80^{\circ} \mathrm{C}$ ). Samples were stored under nitrogen gas at $-20^{\circ} \mathrm{C}$. Where indicated the extraction suspension was supplemented with $1.67 \mathrm{mM}$-PCMB.

Analysis of free and esterified long-chain alcohols. Extracts were fractionated into lipid classes by chromatography on silicic acid columns prepared by a modification of the Naccarato et al. (1972) procedure. Graduated glass pipettes (E-MIL; $5 \mathrm{ml}$ ) were plugged with glass wool and filled with $1 \mathrm{~g}$ SIL-LC silicic acid (325 mesh; lipid chromatography grade) (Hirsch \& Ahrens, 1958). Maximum suction from a water aspirator, applied to the lower end of the column, caused slight compaction of the contents and assured even and reproducible packing. Packed columns were saturated with $20 \mathrm{ml}$ light petroleum by overpressure with high-purity nitrogen gas. Lipid extracts were applied to the top of the column and eluted with $10 \mathrm{ml}$ each of $4 \%, 7 \%$ and $10 \%(\mathrm{v} / \mathrm{v})$ diethyl ether in light petroleum. A flow rate of $0.5 \mathrm{ml} \mathrm{min}^{-1}$ was maintained by nitrogen pressure on the column, and eluates were collected in $3 \mathrm{ml}$ fractions. Fractions were taken to dryness under a stream of nitrogen gas, redissolved in an appropriate volume of light petroleum and $20 \mu \mathrm{l}$ portions spotted onto a $20 \mathrm{~cm} \times 20 \mathrm{~cm} \times 0.25 \mathrm{~mm}$ Silica Gel 60 precoated TLC plate (Merck). The plate was developed with a light petroleum (b.p. $40-60^{\circ} \mathrm{C}$ )/diethyl ether/acetic acid (70:30:1, by vol.) solvent mixture (Mangold, 1969); lipids were located by spraying with $0 \cdot 2 \%$ (w/v) $2^{\prime}, 7^{\prime}$ dichlorofluorescein in ethanol (Griffith et al., 1981) and viewed under ultraviolet $(254 \mathrm{~nm})$ radiation. Standards [1 $\mathrm{mg} \mathrm{m}^{-1}$ light petroleum (b.p. $60-80^{\circ} \mathrm{C}$ )] were cholesterol palmitate, tripalmitin, stearic acid, palmitic acid, hexadecanol, octadecanol and ergosterol. The method gave excellent separation of lipid classes from extracts (Fig. 1). Subsequent analysis of free long-chain alcohols used only fractions $6-9$ from the silicic acid column (Fig. 1). To assay long-chain alcohols, appropriate fractions from the silicic acid column were pooled, concentrated under nitrogen gas and further separated by TLC using a solvent mixture of hexane/diethyl ether/acetic acid (30:70:1, 
by vol.) (Naccarato et al., 1972). Long-chain alcohols were visualized as described above. The appropriate areas of the plate were scraped off and lipids extracted using light petroleum $/ \mathrm{methanol} / 30 \%$ $(w / v) \mathrm{NaCl}(1: 1: 1$, by vol.). Samples were shaken vigorously and allowed to separate. The top layer was removed and the extraction procedure repeated twice. Extracts were pooled and taken to dryness under nitrogen gas.

Long-chain alcohols were separated and identified by GLC after conversion to their trimethylsilyl (TMS) ethers. Samples were taken up in $0.5 \mathrm{ml}$ pyridine, and the solution was mixed with an equal volume of bis(trimethylsilyl)trifluoroacetamide. The mixture was transferred to a $1 \mathrm{ml} \mathrm{screw-top} \mathrm{vial} \mathrm{and} \mathrm{heated} \mathrm{at} 70^{\circ} \mathrm{C}$ for $15 \mathrm{~min}$. Silylated samples were separated using a Pye Unicam PU 4500 gas chromatograph fitted with a $25 \mathrm{~m} \mathrm{SE30}$ capillary column. The injection temperature was $300^{\circ} \mathrm{C}$, and the detector temperature $350^{\circ} \mathrm{C}$. The initial column temperature was $190^{\circ} \mathrm{C}$, and this was increased after $25 \mathrm{~min}$ at a rate of $16^{\circ} \mathrm{C} \mathrm{min}^{-1}$ to give a final temperature of $250^{\circ} \mathrm{C}$ which was maintained for a further $10 \mathrm{~min}$. The carrier gas (helium) flow rate was $1 \mathrm{ml} \mathrm{min}^{-1}$, and the nitrogen fiow rate, as a make-up gas across the detector, was $40 \mathrm{ml} \mathrm{min}{ }^{-1}$. TMS ethers of long-chain alcohols were identified by comparing their retention times with those of known standards and by co-chromatography with authentic standards. Peaks were analysed using a Pye Unicam CDPI computing integrator, and quantified by reference to a 1-heptadecanol internal standard added during the extraction procedure after disruption of organisms. Identification of long-chain alcohols was verified by GLC-MS using electron-impact ionization or chemical ionization. Silylated long-chain alcohols and carboxylic acids were used, and typical outputs of total ion current versus time matched the GLC traces obtained with the Pye Unicam PU 4500 gas chromatograph described above. The instrument used was a VG Analytical 70/70E, with a DB1 capiliary column programmed at $150^{\circ} \mathrm{C}$ for $5 \mathrm{~min}$ and rising to $300^{\circ} \mathrm{C}$ at $30^{\circ} \mathrm{C} \mathrm{min}-1$ for $5 \mathrm{~min}$ and held at the upper temperature. The flow rate of the carrier gas (helium) was $1 \mathrm{ml} \mathrm{min}^{-1}$, the resolution 1000 , the electron impact $70 \mathrm{eV}$ and the calibrated range $20-580$.

To examine the effect of PCMB on extraction of esterified long-chain alcohols, fractions 1-3 from the silicic acid column, which contained neutral lipids, were pooled and applied to Silica Gel 60 plates. Lipids were separated using the solvent system light petroleum-diethyl ether-acetic acid $(90: 10: 1$, by vol.) (Kates, 1972), and visualized as described above. Lipid bands with mobilities similar to heptadecanyl acetate, the internal standard, were scraped off the plate, and the lipids extracted with light petroleum as described above. Samples were then dried under a stream of nitrogen gas, and saponified using a modification of the method of Pollard et al. (1979) by adding $5 \mathrm{ml} 1 \mathrm{M}-\mathrm{KOH}$ in $95 \%(\mathrm{v} / \mathrm{v})$ methanol, sealing and heating at $80^{\circ} \mathrm{C}$ for $3 \mathrm{~h}$. After cooling, samples were diluted with $5 \mathrm{ml}$ methanol, and non-saponifiable lipids removed with $3 \times 5 \mathrm{ml}$ light petroleum. They were then prepared for GLC and analysed as described above.

Analysis of the fatty-acyl composition of lipids. Lipid extracts from organisms were dissolved in chloroform to give approximately $25 \mathrm{mg}$ lipid $\mathrm{ml}^{-1}$. To prepare fatty-acid methyl esters of total lipids from organisms, $1 \mathrm{ml}$ lipid solution was taken to dryness under a stream of nitrogen gas. $\mathrm{BF}_{3}(14 \%, \mathrm{w} / \mathrm{v}$, in methanol; $3 \mathrm{ml})$ was added and the mixture was heated for $1 \mathrm{~h}$ at $80^{\circ} \mathrm{C}$ in a sealed vial. To extract fatty-acid methyl esters, the reaction mixture was made up to $5 \mathrm{ml}$ with methanol and supplemented with $5 \mathrm{ml}$ each of light petroleum and $30 \%(\mathrm{w} / \mathrm{v}) \mathrm{NaCl}$. The solution was shaken vigorously and the mixture left to separate, the procedure being repeated twice more. The solution of fatty-acid methyl esters was taken down to a small volume under a stream of nitrogen gas, streaked onto a $20 \mathrm{~cm} \times 20 \mathrm{~cm} \times 0.25 \mathrm{~mm}$ Silica Gel 60 precoated TLC plate (Merck) and the plate developed with a light petroleum/diethyl ether/formic acid ( $75: 25: 0 \cdot 5$, by vol.) solvent mixture (Fixter et al., 1986). Methyl esters were scraped off the plate, extracted with light petroleum as described above, and taken down to a small volume under a stream of nitrogen gas. Fatty-acid methyl esters were analysed using a fused silica capillary column ( $25 \mathrm{~m}$ length; SGE BP21) in a Pye Unicam GCD chromatograph fitted with an SGE on-column adaptor. The injection temperature was $240^{\circ} \mathrm{C}$ and the detector temperature $280^{\circ} \mathrm{C}$. The column was maintained at $135^{\circ} \mathrm{C}$ for the first $5 \mathrm{~min}$, after which the temperature was raised at the rate of $8^{\circ} \mathrm{C} \mathrm{min}-1$ until it reached $180^{\circ} \mathrm{C}$. The carrier gas was hydrogen. Percentage fatty-acyl compositions were calculated using a Pye Unicam CDPI computing integrator. Individual lipid classes in total lipid extracts were separated by streaking a solution containing $10 \mathrm{mg}$ lipid onto a Silica Gel 60 precoated TLC plate as above, which was developed with a solvent mixture containing light petroleum (b.p. $40-60^{\circ} \mathrm{C}$ )/diethyl ether/acetic acid $(70: 30: 1$, by vol.). Lipid classes were identified as described above, bands scraped off the plates, and fatty-acid methyl esters of the lipids prepared as described above.

Chemicals. All chemicals used were AnalaR or of the highest purity available.

\section{RESULTS}

\section{Identification of long-chain alcohols}

The mobility of certain lipid fractions on silicic acid columns and on TLC (Fig. 1) suggested that their polarity was that expected of long-chain alcohols. Subsequently purification, 


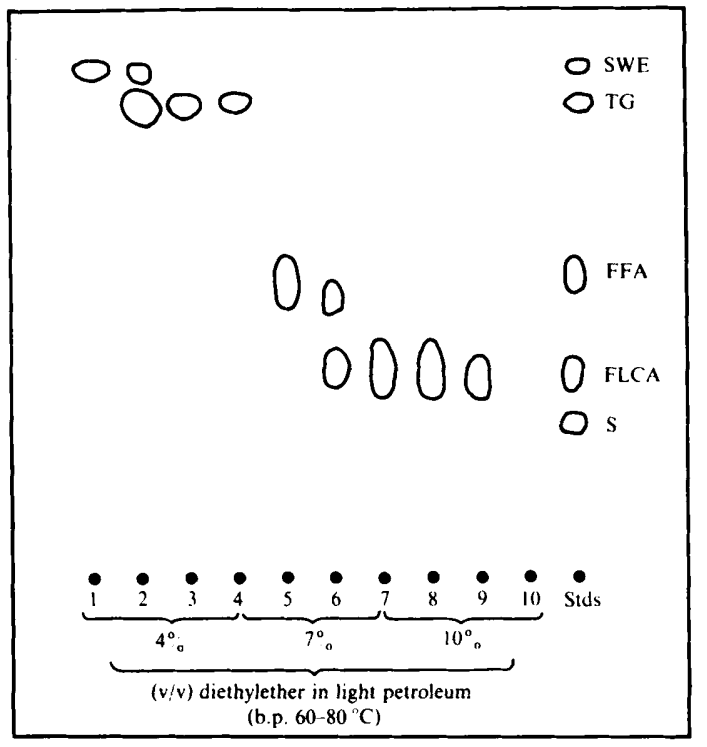

Fig. 1. Drawing of a TLC plate showing separation of lipid classes in each of the ten $3 \mathrm{ml}$ fractions obtained by silicic acid chromatography of a lipid extract of $C$. albicans harvested from cultures after $72 \mathrm{~h}$ growth under anaerobic conditions. SWE, Sterol/wax esters; TG, triacylglycerols; FFA, free fatty acids; FLCA, free long-chain alcohols; S, sterols; Stds, lipid standards.

separation and identification by GLC and GLC-MS confirmed the presence of $\mathrm{C}_{14}, \mathrm{C}_{16}$ and $\mathrm{C}_{18}$ primary alcohols in extracts of organisms. Fig. 2(a) shows the total ion-current trace from GLC-MS of a lipid extract from anaerobically grown C. albicans after purification by TLC. The peak at scan no. 253 was identified as 1-hexadecanol from its fragmentation pattern in electronimpact ionization MS (Fig. $2 b$ ). Peaks 36,115 and 362 were generated by $C_{12}, C_{14}$ and $C_{18}$ longchain alcohols, respectively. Peak 309 was due to the 1-heptadecanol internal standard. Other components of the extract identified were members of the isoprenoid alcohol series (peaks 111 , 128,378 and 403). This latter group of compounds was found in all lipid extracts examined by TLC, and they were also identified in extracts of yeasts that lacked the ability to synthesize longchain alcohols.

\section{Survey of long-chain alcohol production by yeasts}

A survey was made of the ability of 14 strains of yeast to produce long-chain alcohols. Strains were selected partly on the basis of their known ability to metabolize exogenously provided lipids. All strains grew under aerobic conditions although five were unable to do so under anaerobic conditions (Table 1). While some of the strains produced saturated long-chain alcohols, none produced unsaturated long-chain alcohols. Only three yeasts, $C$. albicans, $C$. utilis NCYC 168 and $P$. fermentans, accumulated appreciable amounts of long-chain alcohols when grown either anaerobically or aerobically (Table 1). C. maltosa, C. utilis NCYC 707 and $S$. cerevisiae contained these alcohols when grown anaerobically, but little or no such alcohol after aerobic growth. In general, anaerobic conditions favoured production of long-chain alcohols. Six of the strains with ability to produce the alcohols under these conditions were examined quantitatively for content of $\mathrm{C}_{14}, \mathrm{C}_{16}$ and $\mathrm{C}_{18}$ alcohols (Table 2). The content of $\mathrm{C}_{16}$ alcohols was greatest after anaerobic growth with all of the strains examined. In C. albicans grown under aerobic conditions, $\mathrm{C}_{18}$ alcohol was found in slight excess over $\mathrm{C}_{16}$ alcohol, although the total long-chain alcohol content was about fourfold greater in organisms from anaerobically grown cultures of this yeast. Production of all alcohols, especially $\mathrm{C}_{16}$, was greatest by $C$. albicans grown under anaerobic conditions. 

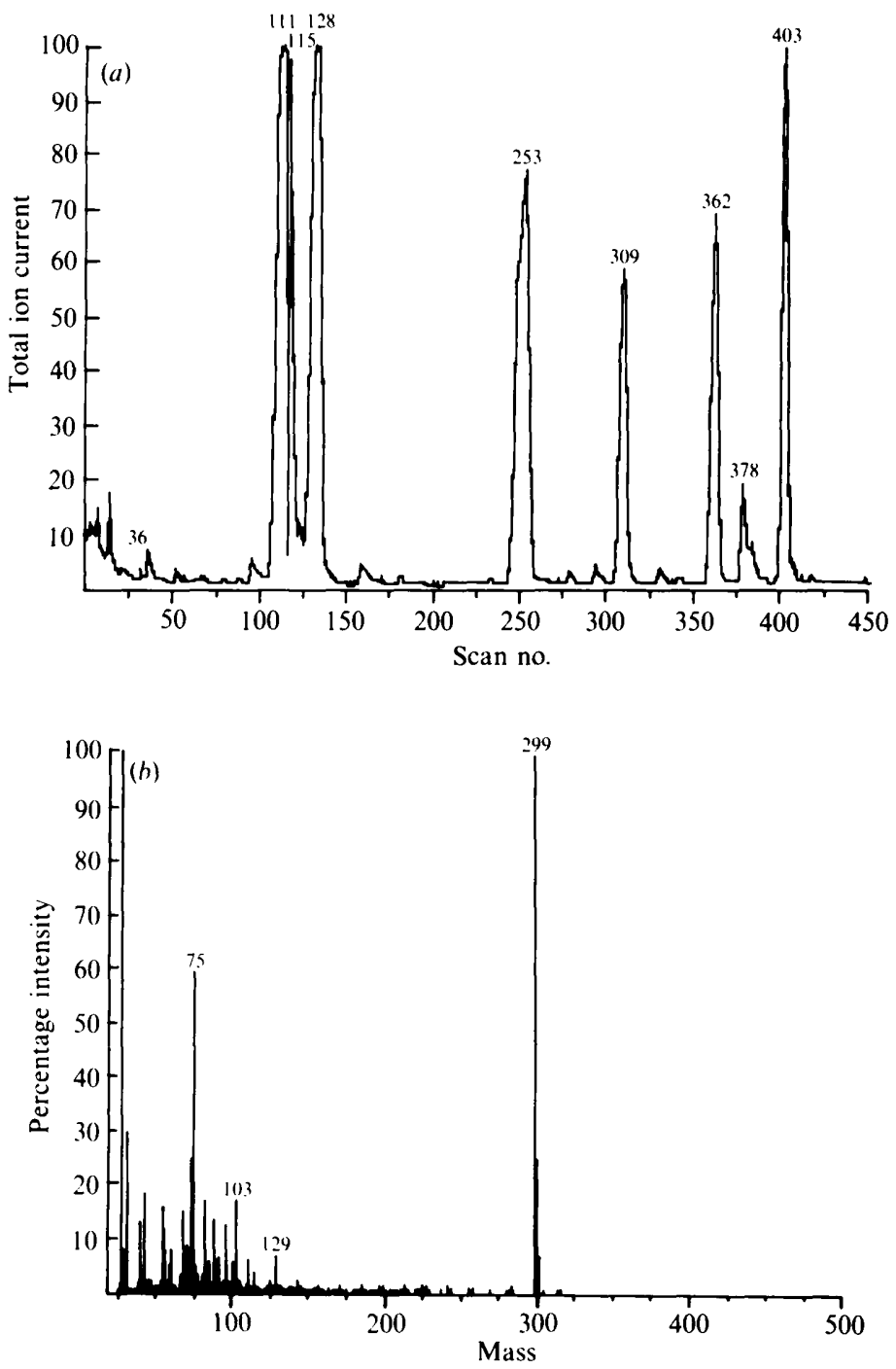

Fig. 2. (a) Total ion-current trace of long-chain alcohol TMS ethers in GLC-MS. Numbers against peaks are scan numbers. (b) Electron-impact ionization mass spectrum of peak scan no. 253 of $(a)$. This peak was recognized as having been generated by hexadecanol. Long-chain alcohols were purified using extracts of $C$. albicans harvested after $168 \mathrm{~h}$ growth under anaerobic conditions.

\section{Long-chain alcohol production by $C$. albicans under anaerobic conditions}

Further studies were confined to $C$. albicans grown under anaerobic conditions. The yeast had a doubling time of $110 \mathrm{~min}$, and reached stationary phase after $48 \mathrm{~h}$ (Fig. 3). Only traces of longchain alcohols were detected in organisms from exponentially growing cultures. However, after cultures entered stationary phase, the contents of $\mathrm{C}_{14}, \mathrm{C}_{16}$, and $\mathrm{C}_{18}$ alcohols increased rapidly until about $170 \mathrm{~h}$ after which alcohol contents remained constant. Rates of increase in alcohol content during stationary phase were greatest for $\mathrm{C}_{16}$ alcohols and smallest for $\mathrm{C}_{14}$ alcohols (Fig. $3)$. Long-chain alcohols were not detected in culture filtrates except after prolonged $(500 \mathrm{~h})$ incubation, when the low concentrations present were probably due to limited lysis of organisms. 
Table 1. Detection of long-chain alcohols in yeasts grown for $72 \mathrm{~h}$ anaerobically or aerobically

Detection in cultures grown:

Yeast

C. albicans NCYC 1467

C. bombicola NCYC 1449

C. maltosa CMCC 3152

C. ingens NCYC 822

C. utilis NCYC 168

C. utilis NCYC 707

D. hansenii NCYC 9

$P$. fermentans NCYC 850

Rh. glutinis NCYC 59

Rh. glutinis CMCC 2272

Rh. rubra NCYC 195

Rhodotorula sp. ATCC 20254

S. cerevisiae $\mathrm{Y} 185$

Saccharomycopsis (Yarrowia)

lipolytica ATCC 20225

\begin{tabular}{|c|c|c|c|c|c|}
\hline \multicolumn{3}{|c|}{ Anaerobically } & \multicolumn{3}{|c|}{ Aerobically } \\
\hline$C_{14: 0}$ & $C_{16: 0}$ & $C_{18: 0}$ & $\mathrm{C}_{14: 0}$ & $C_{16: 0}$ & $C_{18: 0}$ \\
\hline+ & + & + & + & + & + \\
\hline - & - & - & - & - & - \\
\hline \multirow[t]{2}{*}{+} & + & + & - & - & - \\
\hline & No growth & & - & - & - \\
\hline+ & + & + & + & + & + \\
\hline+ & + & + & - & - & - \\
\hline - & - & - & - & - & - \\
\hline+ & + & + & + & + & + \\
\hline \multirow[t]{3}{*}{ - } & - & - & - & - & - \\
\hline & No growth & & - & - & - \\
\hline & No growth & & $+1-$ & $+1-$ & $+1-$ \\
\hline+ & $\begin{array}{c}\text { No growth } \\
+\end{array}$ & + & $+\overline{1-}$ & $+\overline{1-}$ & $+\overline{1-}$ \\
\hline & No growth & $T$ & - & - & 11 \\
\hline
\end{tabular}

Table 2. Long-chain alcohol contents of yeasts

Cultures were grown under anaerobic conditions (except where indicated) for $72 \mathrm{~h}$. Values quoted are the means of three independent determinations \pm SD.

Yeast

C. albicans NCYC 1467

(aerobic)

C. albicans NCYC 1467

C. maltosa CMCC 3152

C. utilis NCYC 168

C. utilis NCYC 707

P. fermentans NCYC 850

S. cerevisiae Y 185
Long-chain alcohol content [ $\mu \mathrm{g}(\mathrm{g} \text { dry wt organisms })^{-1}$ ]

$\begin{array}{rcr}C_{14: 0} & C_{16: 0} & C_{18: 0} \\ 8.76 \pm 0.80 & 18.08 \pm 0.97 & 26.31 \pm 2.03 \\ & & \\ 20.59 \pm 1.79 & 139.29 \pm 10.24 & 34.47 \pm 2.82 \\ 1.76 \pm 0.35 & 47.91 \pm 13.84 & 5.62 \pm 1.01 \\ 3.30 \pm 0.63 & 17.93 \pm 3.47 & 3.92 \pm 0.82 \\ 2.13 \pm 0.72 & 27.05 \pm 9.26 & 4.42 \pm 0.98 \\ 3.25 \pm 0.30 & 28.47 \pm 7.88 & 4.38 \pm 0.68 \\ 0.89 \pm 0.02 & 4.66 \pm 0.48 & 1.35 \pm 0.55\end{array}$

Effect of PCMB on extraction of free and esterified long-chain alcohols from C. albicans

Supplementing cultures with the lipase inhibitor PCMB (Schousboe, 1976) just before harvesting, and including this compound during the extraction procedure up to the stage at which filtered chloroform/methanol extracts were pooled, appreciably decreased the apparent content of all three alcohols (Table 3 ). The possibility that a proportion of the alcohols was esterified was therefore examined using unsupplemented extractions and extractions containing PCMB. Only a small proportion was found to be esterified in this fraction (Table 3).

Fatty-acyl composition of total lipids and lipid classes in C. albicans

The major fatty-acyl residues in all of the fractions analysed (Table 4) were $C_{16}$ and $C_{18}$, including both saturated and unsaturated residues. In the triacylglycerol fractions and in the total lipid extract, the proportion of $\mathrm{C}_{14: 0}$ residues was also high, much more so than in the phospholipid, sterol/wax ester and free fatty-acid fractions. 

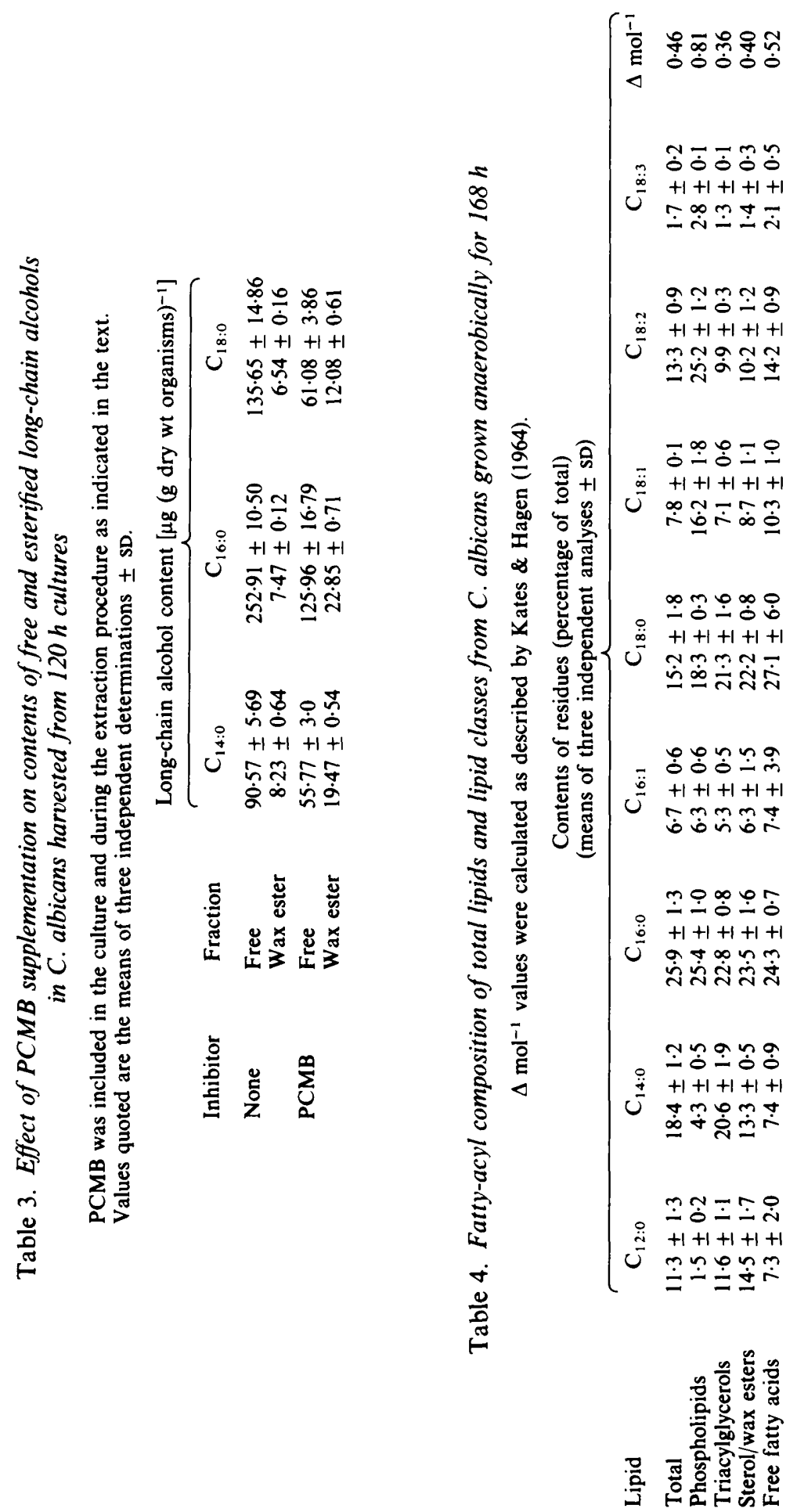


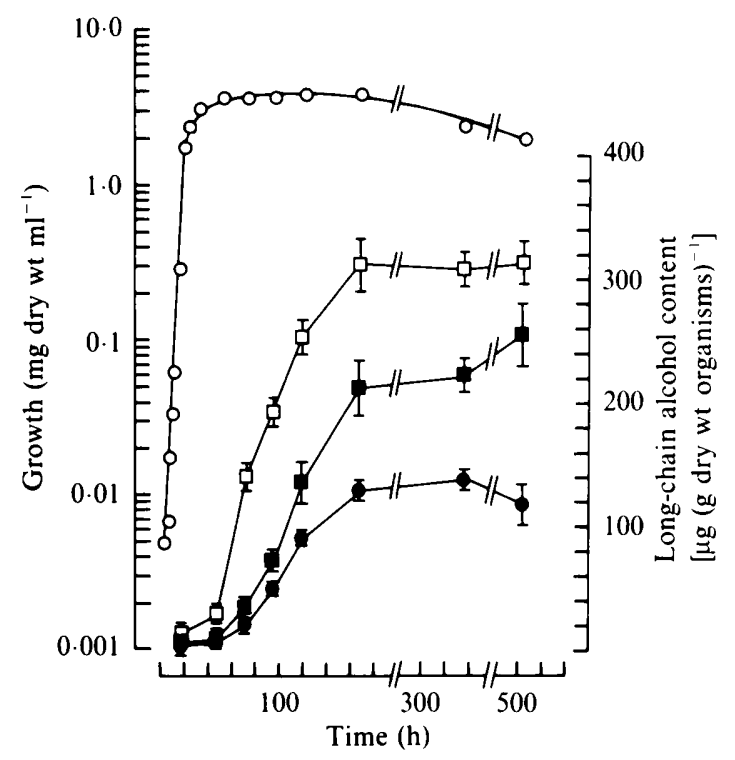

Fig. 3. Time-course of growth $(O)$ of $C$. albicans and of its contents of $C_{14: 0}(O), C_{16: 0}(\square)$ and $C_{18: 0}$ (D) long-chain alcohols. Values quoted are the means of three independent analyses $\pm S D$.

\section{DISCUSSION}

The present paper is the most extensive study published on long-chain alcohols in yeasts. Davidova et al. (1978) reported briefly that glucose-grown $C$. tropicalis synthesizes wax esters. In addition, several reports have appeared of yeast lipid fractions which, from their mobilities, could well be long-chain alcohols (Zalashko et al., 1979; Watanabe \& Takakuwa, 1984), although they are frequently reported as being 'unidentified'. The present report of long-chain alcohol production by C. albicans contrasts with that by Davidova et al. (1978) in that alcohol production was confined to the stationary phase of growth, suggesting that long-chain alcohols in this yeast are secondary metabolites. Naccarato et al. $(1972,1974)$ reported detection of longchain alcohols in Escherichia coli harvested from stationary-phase cultures but they did not describe the time-course of alcohol production.

All of the yeasts which in the present study were shown to produce long-chain alcohols synthesized these compounds with the same chain-length profile, namely $C_{16}>C_{18}>C_{14}$. Traces of $\mathrm{C}_{12}$ alcohol were also detected in some extracts. Significantly, none of the yeasts examined synthesized unsaturated alcohols. The chain-length profile is similar to the fatty-acyl residue profile reported for yeasts in general (Rattray et al., 1975; Kaneko et al., 1976). The fattyacyl composition of total lipid extracts of $C$. albicans, and specifically of the triacylglycerol and sterol/wax ester fractions, was particularly rich in $\mathrm{C}_{14}$ residues, much more so than most other yeasts. It is tempting to suggest that saturated long-chain alcohols arise by reduction of $\mathrm{CoA}$ esters of long-chain carboxylic acids that alternatively would be channelled into other neutral lipids, a route which has been demonstrated in a variety of other organisms (Riendeau \& Meighen, 1985). The switch from incorporation into triacylglycerols and other neutral lipids into long-chain alcohols would appear to be associated with cessation of growth. Synthesis by reduction of long-chain carboxylic acids is the more likely route than $\alpha$-oxidation to the corresponding aldehyde (Fulco, 1967) followed by reduction to the alcohol, since the latter route would yield predominantly odd-chain alcohols which were not detected in any of the yeasts studied.

Synthesis of long-chain alcohols by the yeasts studied was clearly favoured by anaerobic conditions which repress formation of mitochondria (Käppeli, 1986). This might be explained 
by the anaerobic conditions diverting acyl-CoA derivatives to reductive routes. Repression of mitochondrial synthesis would have been increased by the rather high concentration of glucose in the medium used for aerobic and particularly anaerobic growth. Possibly, therefore, mitochondria are, in $C$. albicans, organelles which indirectly exert some type of control over synthesis of long-chain alcohols.

No attempt was made in the present study to establish where long-chain alcohols are located in $C$. albicans. We did, however, try to establish whether and to what extent these alcohols were present in organisms in the free and esterified form. Having discovered that lipid extracts of $C$. albicans contained wax esters, it seemed possible that these esters contained residues of longchain alcohols which might be hydrolysed during extraction of lipids from the yeast. Inclusion of the lipase inhibitor PCMB in the yeast culture and during lipid extraction, although causing a considerable decrease in the content of long-chain alcohols in extracts, did not lead to a corresponding increase in the size of the wax-ester fraction. It is likely, therefore, that long-chain alcohol residues are present in $C$. albicans in some other as yet unknown molecular form.

We are grateful to D. J. Sissons, Unilever Research Laboratories, for mass spectrometry analyses and thank Jill Calderbank for help in preparation of this paper. Our thanks also go to L. Julia Douglas for supplying us with $C$. albicans NCYC 1467 before it was deposited in that culture collection. M. J. White thanks the SERC and Unilever Research for a CASE award.

\section{REFERENCES}

Allen, J. E., Forney, F. W. \& Markovetz, A. J. (1971). Microbial subterminal oxidation of alkanes and alk-1-enes. Lipids 6, 448-452.

BAPtist, J. N., Gholson, R. K. \& CoON, M. J. (1963). Hydrocarbon oxidation by a bacterial enzyme system. I. Products of octane oxidation. Biochimica et biophysica acta 69, 40-47.

Beavan, M. J., Charpentier, C. \& Rose, A. H. (1982). Production and tolerance of ethanol in relation to phospholipid fatty-acyl composition in Saccharomyces cerevisiae. Journal of General Microbiology 128, 1447-1455.

Britton, L. N. (1984). Microbial degradation of aliphatic hydrocarbons. In Microbial Degradation of Organic Compounds, pp. 89-129. Edited by D. T. Gibson. New York: Marcel Dekker.

Davidova, E. G., RaChinskit, V. V. \& Kretova, L. G. (1978). Comparative study of the dynamics of carbohydrate metabolism during the growth of Candida tropicalis on n-octadecane and glucose. Mikrobiologiya 47, 799-804.

Day, J. I. E., Goldfine, H. \& Hagen, P.-O. (1970). Enzymic reduction of long-chain acyl-CoA to fatty aldehyde and alcohol by extracts of Clostridium butyricum. Biochimica et biophysica acta 218, 179182.

Fixter, L. M., Nagi, M. N., McCormack, J. G. \& Fewson, C. A. (1986). Structure, distribution and function of wax esters in Acinetobacter calcoaceticus. Journal of General Microbiology 132, 3147-3157.

Folch, J., Lees, M. \& Sloane Stanley, G. H. (1957). A simple method for the isolation and purification of total lipids from animal tissues. Journal of Biological Chemistry 226, 497-509.

Fulco, A. J. (1967). Chain elongation, 2-hydroxylation and decarboxylation of long chain fatty acids by yeasts. Journal of Biological Chemistry 242, 36083613.

Griffith, T. W., SAND, D. M. \& SCHLENK, H. (1981). Reduction of fatty acids to alcohols in roe of gourami
(Trigogaster cosby). Biochimica et biophysica acta 665 , 34-39.

HaRwood, J. L. \& Russell, N. J. (1984). Lipids in Plants and Microbes. London: George Allen \& Unwin.

Higgins, I. J. \& Gilbert, P. D. (1978). The biodegradation of hydrocarbons. In The Oil Industry and Microbial Ecosystems, pp. 80-117. Edited by K. W. A. Chater \& H. J. Somerville. London: Heyden.

HirsCh, J. \& AHRENS, E. H., JR (1958). The separation of complex lipid mixtures by the use of silicic acid chromatography. Journal of Biological Chemistry 233, 311-320.

Kaneko, H., Hosohara, M., Tanaka, M. \& IToH, T. (1976). Lipid composition of 30 species of yeast. Lipids 11, 837-844.

KäPPELI, O. (1986). Regulation of carbon metabolism in Saccharomyces cerevisiae and related yeasts. Advances in Microbial Physiology 28, 181-209.

KATES, M. (1972). Techniques of lipidology: isolation, analysis and identification of lipids. In Laboratory Techniques in Biochemistry and Molecular Biology, vol. 3, chapter 7, pp. 502-579. Edited by T. S. Work and E. Work. New York: North Holland/American Elsevier.

KATES, M. \& HaGEN, P.-O. (1964). Influence of temperature on fatty acid composition of psychrophilic and mesophilic Serratia spp. Canadian Journal of Biochemistry 42, 481-488.

LLOYD, G. M. \& RusSelL, N. J. (1983). Biosynthesis of wax esters in the psychrophilic bacterium Micrococcus cryophilus. Journal of General Microbiology 129, 2641-2647.

MahadeVan, V. (1978). Fatty alcohols: chemistry and metabolism. Progress in the Chemistry of Fats and Other Lipids 15, 255-299.

Mangold, H. K. (1969). Aliphatic lipids. In Thin Layer Chromatography, pp. 363-421. Edited by E. Stahl. New York: Springer-Verlag.

Muratov, V., Bystrova, M. G., Medvedev, F. A. \& 
KAZANTSEV, YU. E. (1979). Isolation and identification of waxes from lipid extracts of the yeast Candida guilliermondii. Prikladnaya Biokhimiya i Mikrobiologiya 15, 383-388.

Naccarato, W. F., Gelman, R. A., Kawalex, J. C. \& GILBERTSON, J. R. (1972). Characterization and metabolism of free fatty alcohols from Escherichia coli. Lipids 7, 275-281.

Naccarato, W. F., Gilbertson, J. R. \& Gelman, R. A. (1974). In vivo and in vitro biosynthesis of free fatty alcohols in Escherichia coli $\mathrm{K}-12$. Lipids 9 , 419-428.

Patching, J. W. \& Rose, A. H. (1969). The effects and control of temperature. Methods in Microbiology 2, 23-28.

Pollard, M. R., McKeon, T., Gupta, L. M. \& StUMPF, P. K. (1979). Studies on biosynthesis of waxes by developing jojoba seed. II. The demonstration of wax biosynthesis by cell-free homogenates. Lipids 14, 651-662.

RATLEDGE, C. (1976). The physiology of mycobacteria. Advances in Microbial Physiology 13, 115-244.

RATLEDGE, C. (1978). Degradation of aliphatic hydrocarbons. In Developments in Biodegradation of Hydrocarbons, pp. 1-46. Edited by R. J. Watkinson. Barking, U.K.: Applied Science Publishers.

Rattray, J. B. M., SChibeCI, A. \& Kidby, D. K. (1975). Lipids of yeasts. Bacteriological Reviews 39, 197-231.

RAYMond, R. L. \& DAVIS, J. B. (1960). n-Alkane utilization and lipid formation by Nocardia. Applied Microbiology 8, 329-334.

Riendeau, D. \& Meighen, E. (1985). Enzymic reduction of fatty acids and acyl-CoAs to long chain aldehydes and alcohols. Experientia 41, 707-713.

SCHOUSBOE, I. C. (1976). Properties of a triacylglycerol lipase in a mitochondrial fraction from baker's yeast (Saccharomyces cerevisiae). Biochimica et biophysica acta 450, 165-174.

Stewart, J. E. \& Kallio, R. E. (1959). Bacterial hydrocarbon oxidation. II. Ester formation from alkanes. Journal of Bacteriology 78, 726-730.

WatANABE, Y. \& TakakUWa, M. (1984). Effect of sodium chloride on lipid composition of Saccharomyces rouxii. Agricultural and Biological Chemistry 48, 2415-2422.

Wickerham, L. J. (1951). Taxonomy of yeasts. I. Techniques of classification. United States Department of Agriculture Technical Bulletin no. 1029. Washington, DC: US Department of Agriculture.

ZalashKo, M.V. \& Salokhina, G. A. (1982). Intraand extracellular yeast lipids. In Biosintez i Metabolizm Microorganismy. Doklady Vsesoyuznyi Konferentsiya, Second Conference 1979, pp. 23-41. Edited by A. A. Imshenetischki. A. A. Akad Nauk. Moscow USSR: Institute of Microbiology.

ZalashKo, M. V., Romanova, L. V., Gerbeda, V. V. \& PidoplichKo, G. A. (1979). Composition of extracellular lipids in the yeast Rhodotorula glutinis. Mikrobiologiya 48, 230-234. 